\title{
FORUM
}

\section{Is Option B+ the best choice?}

A Coutsoudis, A Goga, C Desmond, P Barron, V Black, H Coovadia

Department of Paediatrics \& Child Health, University KwaZulu-Natal, Durban

A Coutsoudis, $\mathrm{PhD}$

Medical Research Council, Pretoria

A Goga, FC (Paeds)

School of Clinical Medicine, University of the Witwatersrand, Johannesburg

C Desmond, $\mathrm{PhD}$

School of Public Health, University of the Witwatersrand, Johannesburg

P Barron, FFCH

Wits Reproductive Health and HIV Institute, University of the Witwatersrand, Johannesburg

V Black, MB BCh

MatCH, University of the Witwatersrand, Johannesburg

H Coovadia, MD

Corresponding author: A Coutsoudis (coutsoud@ukzn.ac.za)

This article is reprinted from The Lancet, with permission from Elsevier: Coutsodis A, Goga A, Desmond C, Barron P, Black V, Coovadia H. Is Option B+ the best choice? Lancet 2013;381(9863):269-271. [http://dx/doi.org/10.1016/S0140-6736(12)61807-8]

The success of prevention of mother-to-child transmission (PMTCT) programmes (Options A and B) in middle-income countries, together with clinical trial data on antiretroviral (ARV) treatment as prophylaxis, has emboldened UN agencies to aggressively promote lifelong ARVs for PMTCT (Option B+). Unsubstantiated claims submit that Option B+ is cost-effective at population-level, will protect HIV-negative male partners, improve maternal and infant health, and increase ARV coverage. We provide counterfactual arguments about the ethics, medical safety, programme feasibility and economic benefits of Option B+.

Option B+ offers no advantage to PMTCT and there are social hazards associated with privileging pregnant woman for treatment over men and non-pregnant women, especially with the absence of data to suggest that discordant relationships are more frequent among pregnant women or that they contribute disproportionately to the horizontal HIV transmission. The benefits and safety of long-term ARVs - including adherence and resistance - in mothers who do not need treatment for their own health, need to be considered, as well as, crucially, health service costs. The assumption that a decrease in efficiency caused by inappropriate targeting is compensated for by lower recruitment costs, is untested. Lives could be saved instead with appropriately targeted interventions. Countries should make individual decisions based on their HIV epidemiology, resources, priorities and local evidence.

S Afr J HIV Med 2013;14(1):8-10. DOI:10.7196/SAJHIVMED.898

Advocacy of the extreme antiretroviral therapy (ART) Option $\mathrm{B}+$ for pregnant women by some organisations and international agencies, ${ }^{[1,2]}$ particularly at the AIDS 2012 conference in Washington DC, USA, ${ }^{[3]}$ with little consultation, debate and discussion, is worrying.

Supporters of Option B+ argue that it is superior, owing to additional ART coverage (because CD4 cell count results are not needed), additional maternal health benefits, and protection of discordant male partners. However, these benefits have not been validated due to the fast pace and single-mindedness of advocacy. The business case, ${ }^{[2]}$ which supports the use of Option B+ in resource-limited settings, does not fully address four critical considerations: ethics, medical safety and benefits, programme feasibility, and economic concerns (Table 1).
Options A, B and B+ have similar protective benefits with respect to the prevention of mother-to-child transmission (PMTCT) of HIV. ${ }^{[4,5]}$ Data suggest that triple ART may provide maternal health benefits even up to CD4 cell counts of 600 cells $/ \mu \mathrm{l},{ }^{[5,6]}$ and that it reduces HIV transmission between discordant couples. ${ }^{[7]}$

However, these data alone do not justify favouring pregnant woman for treatment over men and non-pregnant women. If Option B+ is used because it may decrease mortality and disease progression in HIV-infected mothers with CD4 counts $>350$ cells/ $\mu \mathrm{l}$, then the justification should extend to the families, partners, friends and community of the pregnant women, and the whole HIV-infected population. The application of different treatment thresholds in sub-populations could create tensions 
Table 1. Summary of PMTCT options and concerns with Option B+

\begin{tabular}{|c|c|}
\hline \multicolumn{2}{|c|}{ PMTCT options } \\
\hline \multicolumn{2}{|l|}{ Option A } \\
\hline Mother & 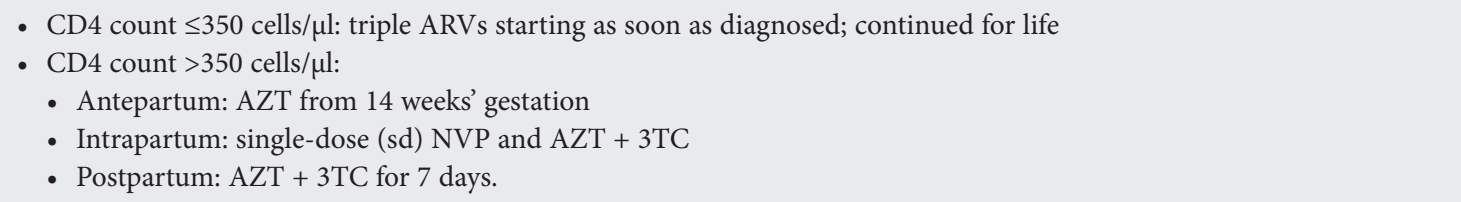 \\
\hline Infant & - Daily sd NVP for 6 weeks in non-BF infants or mother receiving ART or until 1 week after all BF has stopped. \\
\hline \multicolumn{2}{|l|}{ Option B } \\
\hline Mother & $\begin{array}{l}\text { - All pregnant women will be started on triple ARVs regardless of CD4 cell count. } \\
\text { - CD4 count } \leq 350 \text { cells/ } \mu \text { l: triple ARVs will be continued for life } \\
\text { - CD4 count }>350 \text { cells/ } \mu \text { l: triple ARVs will be started as early as } 14 \text { weeks' gestation, continued intrapartum and } \\
\text { through childbirth and stopped if not breastfeeding or continued until } 1 \text { week after cessation of all breastfeeding. }\end{array}$ \\
\hline Infant & - Daily NVP or AZT from birth to 4 - 6 weeks of age. \\
\hline \multicolumn{2}{|l|}{ Option B+ } \\
\hline Mother & - All pregnant women will be started on triple ARVs regardless of CD4 cell count and this will be continued for life. \\
\hline Infant & - Daily NVP or AZT from birth to 4 - 6 weeks of age. \\
\hline \multicolumn{2}{|c|}{ Concerns with Option B+ } \\
\hline Ethical & $\begin{array}{l}\text { - Should pregnant women be prioritised for treatment for reasons other than the immediacy of their medical condition? } \\
\text { - Have the implications of introduction or exacerbation of intra-household and community tensions because of different } \\
\text { treatment access been adequately considered? } \\
\text { - Should selective test-and-treat interventions be considered ahead of achieving universal access for patients with CD4 } \\
\text { counts }<350 \text { cells/ } \mu \text { ? } \\
\text { - Is it ethical to give women with high CD4 cell counts treatment for life without fully understanding the long-terms } \\
\text { benefits and risks? } \\
\text { - Will the rollout of ARVs for a selected group within the population compromise the provision of ARVs for other } \\
\text { groups who need it for their own health in resource-limited settings or settings with drug-supply restrictions? }\end{array}$ \\
\hline Medical & $\begin{array}{l}\text { - Are there benefits for mother-to-child transmission and long-term infant HIV-free survival? } \\
\text { - Are the benefits for maternal health worth the potential increase in drug resistance? } \\
\text { - Will long-term exposure to ARVs in mothers reduce horizontal transmission and change the trajectory of the HIV epidemic? } \\
\text { - Do we have enough evidence to suggest that pregnant women and new mothers are a risk group who have discordant } \\
\text { relationships and contribute to the HIV epidemic? }\end{array}$ \\
\hline Programmatic & $\begin{array}{l}\text { - Can B+ be implemented in strained health systems without disruption of the introduction of treatment programmes? } \\
\text {-Will the implementation of B+ need scarce resources such as personnel, laboratory support and drugs to be diverted } \\
\text { from the drive towards universal access to HIV treatment or universal access to treatment for other non-HIV life- } \\
\text { threatening conditions or infectious diseases? } \\
\text { - Will the necessary levels of adherence be maintained? }\end{array}$ \\
\hline Economic & $\begin{array}{l}\text { - Is the assumption valid that economies of scope will favour this } 3 \text {-in- } 1 \text { intervention (i.e. PMTCT, treatment and } \\
\text { treatment-as-prevention)? } \\
\text { - If retention rates are not high, will the economic argument in favour of } \mathrm{B}+\text { be invalid? }\end{array}$ \\
\hline
\end{tabular}

between people with and those without access to treatment. If Option $\mathrm{B}+$ is a phase-in of a universal test-and-treat goal, then this should be made explicit, and the ethics of early treatment initiation in the context of unmet need warrant discussion. Option B+ is being considered only in resource-limited settings with a high HIV burden, to target pregnant women for non-pregnancy-related interventions such as treatment-asprevention and early treatment initiation. There are no data to suggest that pregnant women have above-average involvement in discordant relationships or that pregnant women contribute disproportionately to the horizontal transmission of HIV.
The medical benefits and safety of long-term antiretrovirals (ARVs) need to be considered, including adherence and resistance, in subpopulations of mothers and infants who do not need treatment for their own health. For example, increased exposure to ART, as will be experienced with Options B or B+, may increase adverse pregnancy outcomes such as pre-term delivery and low birth weight. ${ }^{[8]}$ In resourcelimited settings this may increase risk for infant death. Increased exposure to tenofovir may also increase potential for renal toxicity in mothers ${ }^{[0]}$ and poor growth outcomes in infants. ${ }^{[10]}$ Additionally, Option B+ is costly, owing to the need for additional drugs, laboratory tests, human resources 
and other health-system expenditures. Furthermore, experience of Option B+ is restricted to Malawi and Rwanda; this is insufficient to measure universal feasibility. The success of Option B+ depends on the retention of women in treatment programmes, which increases pressure on already strained health systems. ${ }^{[1,1,12]}$ Recent data show that adequate adherence drops from $75.7 \%$ (95\% CI: 71.5 - 79.7\%) during pregnancy to 53\% (95\% CI 32.8 - 72.7) postpartum among women who meet present ART criteria. ${ }^{[13]}$ The public health implications (including resistance and potential for future treatment) of reduced adherence in Options B and especially $\mathrm{B}+$ are unknown and likely to be concerning. Finally, although higher treatment thresholds may be necessary, particularly in regions with high fertility rates, it is unclear whether universal provision of ART for pregnant women only is appropriate.

The business case for Option B+ assumes that economies of scope are generated by implementation of the triple combination of PMTCT of HIV, treatment and treatment-as-prevention. If each intervention were to be introduced separately, except for PMTCT, then the targeting of pregnant women only would not be appropriate. The recommendation of Option $\mathrm{B}+$ is based on the untested assumption that the decrease in efficiency caused by inappropriate targeting is compensated for by lower recruitment costs. Similar to the economic analysis of Testand-Treat, ${ }^{[14]}$ small changes to assumptions, particularly relating to retention, have large implications. Indeed, if the scope assumptions are incorrect, Option B+ will cost lives, which could have been saved with appropriately targeted treatment and treatment-as-prevention.

Advocacy is critical, and reliance only on what has been scientifically proven would result in slow progress. However, with so many unknowns, the strong push for countries to switch to Option B+ is premature. A switch now would be dangerous, ignoring severe ethical, safety, feasibility and economic concerns. Countries should make their own decisions based on their local situation, resources, priorities and evidence. International agencies should guide, but not pressure, ministries into making decisions, particularly where evidence is weak. A clear decision-making process is essential.

Acknowledgements. This article is reprinted from The Lancet, with permission from Elsevier: Coutsodis A, Goga A, Desmond C, Barron P, Black V, Coovadia H. Is Option B+ the best choice? Lancet 2013;381(9863):269271. [http://dx/doi.org/10.1016/S0140-6736(12)61807-8]

Conflict of interest. AC is a member of the protocol team of the PROMISE study, which is investigating the research questions associated with Option
B v. Option A. HC has received funding for breastfeeding research from the Welcome Trust and NIH. Other authors declared no conflicts of interest.

\section{References}

1. World Health Organization HIV/AIDS Programme. Use of antiretroviral drugs for treating pregnant women and preventing HIV infections in infants. Executive Summary. Geneva: WHO, 2012. http://www.who.int/hiv/PMTCT_update.pdf (accessed 8 October 2012)

2. UNICEF. A Business case for Options B and B+ to eliminate mother to child transmission of HIV by 2015. A Discussion Document for the Global Steering Group Presented by the Business Leadership Council and UNICEF, in Collaboration with the Clinton Health Access Initiative. New York: UNICEF, 2012. http://eptctasiapacific. org/content/business-case-options-b-and-b-eliminate-mother-child-transmissionhiv-2015-model-methodology (accessed 3 October 2012)

3. AIDS 2012. Washington DC. July, 2012. http://aids2012.org/WebContent/File/ AIDS2012_Plenary_Media_Release_25_July_2012_EN.pdf (accessed 8 October 2012)

4. Shapiro R, Hughes M, Oguwa A. Antiretroviral Regimens in Pregnancy and Breast-Feeding in Botswana. N Engl J Med 2010;362(24):2282-2294. [http://dx.doi. org/10.1056/NEJMoa0907736]

5. The Kesho Bora study group. Triple antiretroviral compared with zidovudine and single-dose nevirapine prophylaxis during pregnancy and breastfeeding for prevention of mother-to-child transmission of HIV-1 (Kesho Bora study): A randomised controlled trial. Lancet Infect Dis 2011;11(3):171-180. [http://dx.doi. org/ 10.1016/S1473-3099(10)70288-7]

6. Hargrove J, Humphrey J; ZVITAMBO Study Group. Mortality among HIV-positive postpartum women with high CD4 cell counts in Zimbabwe. AIDS 2010;24:F1114. [http://dx.doi.org/10.1097/QAD.0b013e328335749d]

7. Cohen M, Chen Y, McCauley M, et al. Prevention of HIV-1 infection with early antiretroviral therapy. N Engl J Med 2011;365(6):493-505. [http://dx.doi. org/10.1056/NEJMoa1105243]

8. Chen JY, Ribaudo HJ, Souda S, et al. Highly Active Antiretroviral Therapy and Adverse Birth Outcomes Among HIV-Infected Women in Botswana. J Infect Dis 2012;206:1695-1705. [http://dx.doi.org/10.1093/infdis/jis553]

9. Struik GM, den Exter RA, Munthali C, et al. The prevalence of renal impairment among adults with early HIV disease in Blantyre, Malawi. Int J STD AIDS 2011;22(8):457-462. [http://dx.doi.org/10.1258/ijsa.2011.010521]

10. Siberry G, Williams P, Mendez H, et al.; Pediatric HIV/AIDS Cohort study (PHACS). Safety of tenofovir use during pregnancy: Early growth outcomes in HIV-exposed uninfected infants. AIDS 2012;26(9):1151-1159. [http://dx.doi. org/10.1097/QAD.0b013e328352d135]

11. Rosen S, Fox M, Gill C. Patient retention in antiretroviral therapy prorams in SubSaharan Africa: A systematic review. PLoS Med 2007;4(10):1691-1701. [http:// dx.doi.org/10.1371/journal.pmed.0040298]

12. Unge C, Södergård B, Marrone G. Long-term adherence to antiretroviral treatment and program drop-out in a high-risk urban setting in sub-Saharan Africa: A prospective cohort study. PLoS ONE 2010;5(10):1-12. [http://dx.doi.org/10.1371/ journal.pone.0013613]

13. Nachega J, Uthman $\mathrm{O}$, Anderson J, et.al. Adherence to antiretroviral therapy during and after pregnancy in low-, middle- and high-income countries: A systematic review and meta-analysis. AIDS 2012;26(16):3039-3052. [http://dx.doi. org/101097/QAD0b013e328359590f]

14. Wagner B, Blower S. Universal Access to HIV Treatment versus Universal 'Test and Treat': Transmission, Drug Resistance \& Treatment Costs. PLoS One 2012;7(9):e41212. [http://dx.doi.org/10.1371/journal.pone.0041212] 